\title{
A Climatology of the Tropospheric Thermal Stratification Using Saturation Potential Vorticity
}

\author{
Robert L. KORTY* AND TAPIO SCHNEIDER \\ California Institute of Technology, Pasadena, California
}

(Manuscript received 27 November 2006, in final form 10 April 2007)

\begin{abstract}
The condition of convective neutrality is assessed in the troposphere by calculating the saturation potential vorticity $P^{*}$ from reanalysis data. Regions of the atmosphere in which saturation entropy is constant along isosurfaces of absolute angular momentum, a state indicative of slantwise-convective neutrality, have values of $P^{*}$ equal to zero. In a global reanalysis dataset spanning the years 1970-2004, tropospheric regions are identified in which $P^{*}$ is near zero, implying that vertical convection or slantwise convection may be important in determining the local thermal stratification. Convectively neutral air masses are common not only in the Tropics but also in higher latitudes, for example, over midlatitude continents in summer and in storm tracks over oceans in winter. Large-scale eddies appear to stabilize parts of the lower troposphere, particularly in winter.
\end{abstract}

\section{Introduction}

The thermal stratification of the troposphere influences the energies and scales of eddies and affects climate sensitivity (e.g., Manabe and Wetherald 1975), which underscores the importance of understanding the processes that establish and maintain the stratification. The troposphere's depth and thermal stratification are governed by an equilibrium between radiative processes and dynamical entropy fluxes. In the Tropics, moist convection maintains the thermal stratification in an approximately convectively neutral state, which is characterized by vertical temperature profiles that follow moist adiabats (e.g., Sarachik 1985; Xu and Emanuel 1989). In the extratropics, both large-scale dynamics and convection can contribute to the maintenance of the thermal stratification.

Early ideas regarding the extratropical thermal stratification focused on the role of dry dynamics (e.g., Held 1982). Large-scale eddies transport entropy poleward and upward in baroclinically unstable regions and thus

\footnotetext{
* Current affiliation: Department of Atmospheric Sciences, Texas A\&M University, College Station, Texas.
}

Corresponding author address: Robert L. Korty, Department of Atmospheric Sciences, Texas A\&M University, 3150 TAMU, College Station, TX 77843-3150.

E-mail: korty@alum.mit.edu

DOI: 10.1175/2007JCLI1788.1

(C) 2007 American Meteorological Society increase the static stability and reduce the meridional temperature gradient. Many authors have argued that neutrality with respect to baroclinic instability may characterize the thermal structure of the extratropical troposphere, implying a linear relation between midtropospheric vertical and meridional potential temperature gradients (e.g., Stone 1978; Lindzen et al. 1980; Held 1982; Gutowski 1985; Gutowski et al. 1989; Lindzen 1993; Stone and Nemet 1996). But there is no basis to expect that eddies would generally maintain the atmosphere in a state that is neutral with respect to linear baroclinic instability since baroclinic instability can equilibrate nonlinearly and produce a dynamical equilibrium that is linearly unstable (cf. Vallis 1988). There is abundant evidence that the atmosphere is not in a baroclinically neutral state (e.g., Valdes and Hoskins 1989; Barry et al. 2000). Still, eddies may play a role in maintaining the extratropical thermal stratification. For example, GCM simulations by Barry et al. (2000) show that eddies stabilize the troposphere, most effectively below about $700 \mathrm{hPa}$. And simulations with an idealized GCM by Schneider and Walker (2006) likewise show that eddies can stabilize the lower troposphere and can stabilize the entire troposphere if the baroclinicity is sufficiently large (see also Schneider 2004, 2007).

Convection occurs frequently in the extratropics and may be important to the thermal stratification. However, Stone and Carlson (1979) show that, in the zonal 

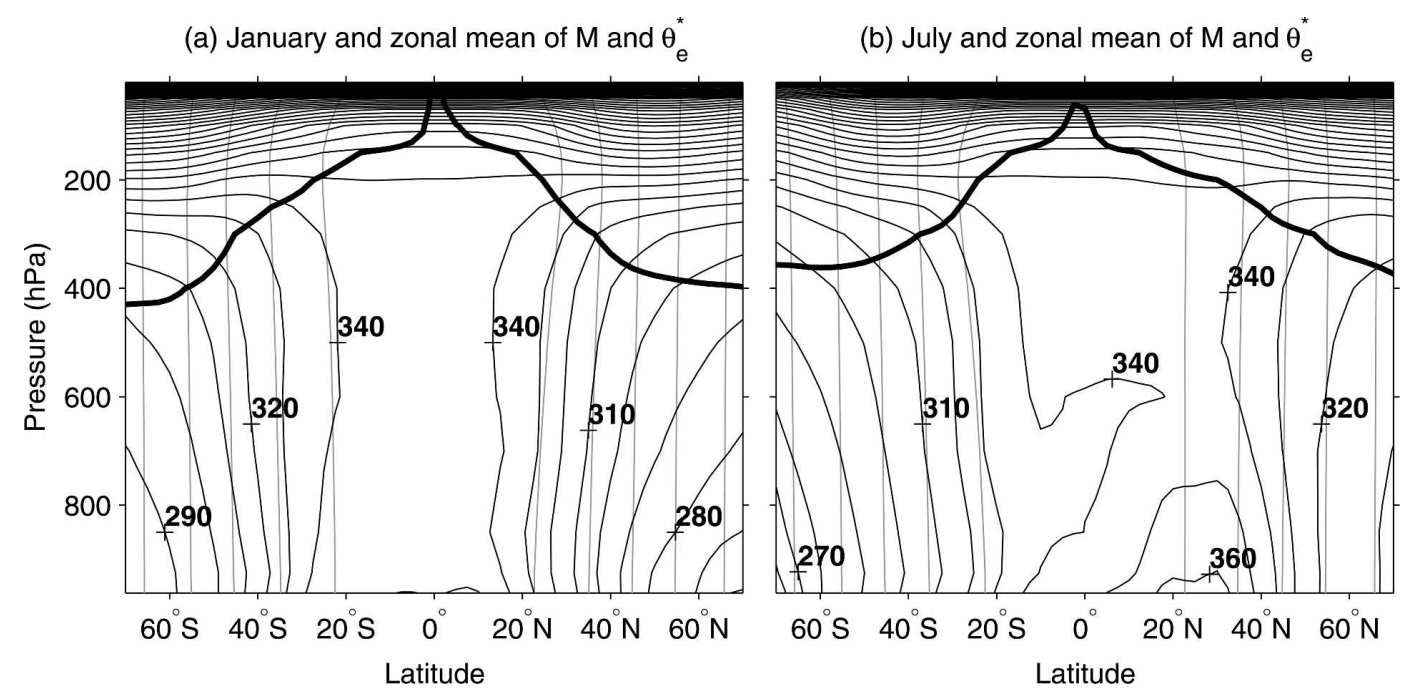

FIG. 1. (a) January and zonal mean angular momentum $M$ (light gray) and saturation equivalent potential temperature $\theta_{e}^{*}$ (black). The 1.5-PVU contour, indicating the tropopause in the extratropics, is drawn with a thick black line. (b) Same as in (a), but for July.

mean, the tropospheric thermal stratification in the Northern Hemisphere is moist adiabatic only equatorward of about $30^{\circ} \mathrm{N}$ in January and equatorward of about $50^{\circ} \mathrm{N}$ in July. Poleward of these latitudes, vertical temperature profiles are more stable than moist adiabats in the zonal mean, particularly in the lower troposphere (Schneider 2007). For convection to be important in the maintenance of the extratropical stratification, deep moist convection must be common in mid- and high latitudes, as is observed, for example, over continents in summer and over oceans in winter. Of course, both convection and eddies can influence the extratropical thermal stratification, but one process may dominate the other at various times and in various regions, or, as proposed by Juckes (2000), they may jointly determine the thermal stratification.

Slantwise moist convection should also be considered in addition to vertical convection. In analogy to convection driven by gravitationally unstable vertical displacements of moist air masses, convection can be driven by symmetrically unstable slantwise displacements of moist air masses if moist entropy decreases upward along slanted isosurfaces of absolute angular momentum (Bennetts and Hoskins 1979; Emanuel 1983a,b). In the atmosphere, convection may be driven by either or both of these instability mechanisms (Emanuel 1994). In baroclinic regions, a parcel that is stable to vertical displacements may nevertheless be unstable to slantwise displacements (Emanuel 1983a, 1988). Slantwise moist convection, possibly generating three-dimensional turbulent motions, establishes moistadiabatic temperature lapse rates along angular momentum surfaces (Thorpe and Rotunno 1989), and it acts on time and space scales that are intermediate between those of vertical moist convection and baroclinic instability (Emanuel 1983a). Emanuel (1988) showed that ascent regions in extratropical cyclones exhibit approximately moist-adiabatic lapse rates along angular momentum surfaces, providing evidence for the occurrence of slantwise moist convection.

To illustrate that vertical or slantwise convection can be important in the extratropical atmosphere, Fig. 1 shows the saturation equivalent potential temperature $\theta_{e}^{*}$ and the zonal and monthly mean angular momentum $M$, which is defined as

$$
M=\Omega a^{2} \cos ^{2} \phi+u a \cos \phi,
$$

where $\Omega$ is the planetary angular velocity, $a$ is the planetary radius, and $\phi$ is latitude. These quantities were computed for each day in January between 1970 and 2004 from the National Centers for Environmental Prediction-National Center for Atmospheric Research (NCEP-NCAR) reanalysis (Kalnay et al. 1996) and then averaged to form a zonal and temporal mean; the data and details regarding the calculation of $\theta_{e}^{*}$ are discussed further in section 2. In the zonal and temporal mean, conditions nearly neutral to slantwise convection, in which $\theta_{e}^{*}$ is nearly constant along $M$ surfaces, can be found equatorward of about $30^{\circ}$ latitude in January. In July, nearly neutral conditions can be found through the midlatitudes of the Northern Hemisphere. Note that, in the zonal mean, angular momentum contours are nearly vertical in the extratropics, but there can be deviations locally, as was shown by Emanuel (1988). 
We present an observational assessment of where and when the extratropical thermal stratification is nearly neutral to vertical convection or slantwise convection. (In what follows, we use the term convection to refer collectively to vertical and slantwise convection.) While such an assessment does not isolate the effects of convection on the thermal stratification from largescale dynamics, it generates a climatology of the times and locations of occurrence of air masses with convectively neutral stratification. Most of these areas were likely adjusted by convection.

\section{Saturation potential vorticity}

Ertel's (1942) potential vorticity $P$ is conserved in the absence of friction and heating and can be inverted to retrieve information about the balanced wind and mass fields. It is defined as

$$
P=\frac{(2 \boldsymbol{\Omega}+\boldsymbol{\nabla} \times \mathbf{u}) \cdot \boldsymbol{\nabla} \theta}{\rho},
$$

where $(2 \boldsymbol{\Omega}+\boldsymbol{\nabla} \times \mathbf{u})$ is the absolute vorticity vector, $\theta$ is potential temperature, and $\rho$ is density. The virtual potential temperature $\theta_{v}$ can be used in place of $\theta$ to account for the dependence of density on water vapor concentration (Schubert et al. 2001).

In this paper, we are interested in a simple diagnostic to assess the alignment of saturation entropy and angular momentum surfaces, as seen in Fig. 1. We use the saturation potential vorticity $P^{*}$, which Emanuel (2008) proposed for this type of analysis. It is defined much like Ertel's potential vorticity in (2), but with the saturation equivalent potential temperature $\theta_{e}^{*}$ in place of the dry (or virtual) potential temperature:

$$
P^{*}=\frac{(2 \boldsymbol{\Omega}+\boldsymbol{\nabla} \times \mathbf{u}) \cdot \boldsymbol{\nabla} \theta_{e}^{*}}{\rho} .
$$

(Alternatively, $\theta_{e}^{*}$ could be replaced with $\ln \theta_{e}^{*}$, which is proportional to the saturation entropy $s^{*}$, but we choose the former because of its similarity to the classic Ertel form. Using $s^{*}$, which does not depend on the absolute value of $\theta_{e}^{*}$, does not qualitatively affect those of our results that are based on threshold values of $\left.P^{*}.\right)^{1}$ The saturation equivalent potential temperature is the equivalent potential temperature $\theta_{e}$ a parcel

\footnotetext{
${ }^{1}$ Several variations of Ertel's vorticity have been used for moist applications: Bennetts and Hoskins (1979) discussed a closely related version that uses the wet-bulb potential temperature, and Emanuel (1983a) used a variant with equivalent potential temperature. Each has uses and limitations that vary with specific application (see Schubert et al. 2001 for an additional discussion).
}

would have if it were saturated at the same temperature and pressure; it is defined as (Emanuel 1994, p. 120)

$$
\theta_{e}^{*}=T\left(\frac{p_{o}}{p_{d}}\right)^{R_{d^{\prime}}\left(c_{\mathrm{pd}}+c_{l} r_{t}\right)} \exp \left[\frac{L r^{*}}{\left(c_{\mathrm{pd}}+c_{l} r_{t}\right) T}\right],
$$

where $T$ is temperature, $p_{o}$ is a reference pressure $(1000 \mathrm{hPa}) ; p_{d}$ is the partial pressure of dry air (the difference between the total pressure $p$ and the saturation vapor pressure $\left.e^{*}\right) ; R_{d}$ is the gas constant for dry air; $c_{\mathrm{pd}}$ and $c_{l}$ are the heat capacities for dry air and water, respectively; $r_{t}$ is the total water mixing ratio; $r^{*}$ is the saturation mixing ratio; ${ }^{2}$ and $L$ is the latent heat (of vaporization or sublimation, depending on temperature). To compute $\theta_{e}^{*}$, we first compute an effective saturation vapor pressure $e^{*}$ and latent heat $L$ using the relations of Simmons et al. (1999), which are based on saturation over ice and sublimation for temperatures below $-23^{\circ} \mathrm{C}$, on saturation over liquid water and vaporization for temperatures over $0^{\circ} \mathrm{C}$, and quadratic interpolations for intermediate temperatures. We then use this effective saturation vapor pressure and latent heat to calculate $\theta_{e}^{*}$ in (4).

Expanding (3) in pressure coordinates and making the hydrostatic approximation yields

$$
P^{*}=-g\left[-\frac{\partial v}{\partial p} \frac{\partial \theta_{e}^{*}}{\partial x}+\frac{\partial u}{\partial p} \frac{\partial \theta_{e}^{*}}{\partial y}+(f+\zeta) \frac{\partial \theta_{e}^{*}}{\partial p}\right]
$$

where $\zeta=\partial_{x} v-\partial_{y} u$ is the relative vorticity. Ertel's dry potential vorticity can be approximated by the analog of the third term alone $\left[-g(f+\zeta) \partial_{p} \theta\right]$, but here we include the horizontal gradients of $\theta_{e}^{*}$ as well. Horizontal gradients of $\theta_{e}^{*}$ along a pressure surface cannot be smaller than horizontal gradients of $\theta$, as $\theta_{e}^{*}-\theta$ is larger in warm air masses than in cold ones. Additionally, vertical gradients of $\theta_{e}^{*}$ are smaller than those of $\theta$, which means that the ratios of the third term in the saturation potential vorticity in (5) to the first two terms are smaller than the analogous ratios in Ertel's dry potential vorticity. In the extratropical troposphere, $f \partial_{p} \theta_{e}^{*}$ is the dominant term in the saturation potential vorticity in (5), and $\zeta \partial_{p} \theta_{e}^{*}$ is smaller by a factor of order Rossby number. The second term $\left(\partial_{p} u \partial_{y} \theta_{e}^{*}\right)$ is of the same order of magnitude as $\zeta \partial_{p} \theta_{e}^{*}$ and should be included. The first term $\left(-\partial_{p} v \partial_{x} \theta_{e}^{*}\right)$ is often an order of magnitude smaller than the others, but we retain it for quantitative accuracy. As we show in section 5, it is crucial to include the horizontal terms in regions characterized by slantwise-convective (as distinct from vertical-convective) neutrality. In all calculations, we use

\footnotetext{
${ }^{2}$ Because we do not consider liquid water content in our analysis, $r_{t}$ will equal $r^{*}$ in (4).
} 
(a) January and zonal mean $\mathrm{P}_{+}$

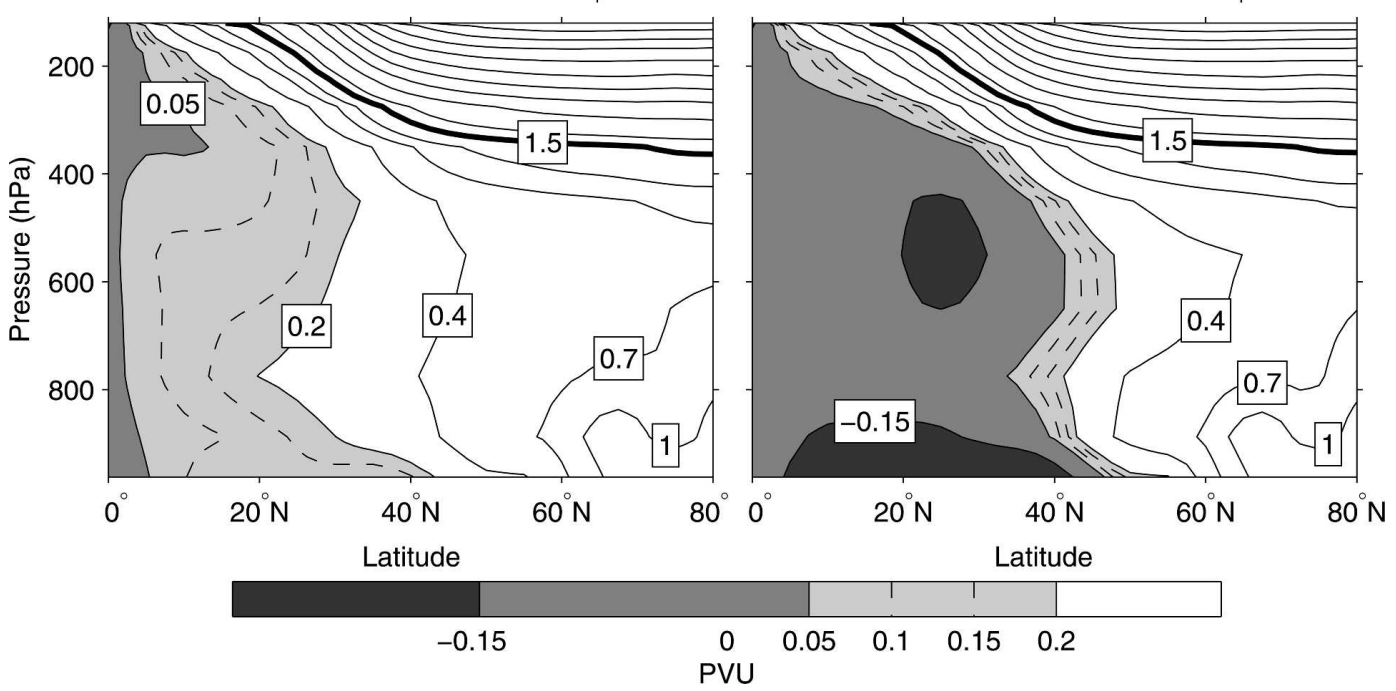

FIG. 2. January and zonal mean values of (a) Ertel's potential vorticity and (b) saturation potential vorticity. Values between 0.05 and $0.2 \mathrm{PVU}$ are shaded light gray and the 0.1- and 0.15-PVU contours are dashed; the 1.5-PVU contour is drawn with a thick black line.

the spherical-coordinate analog of the local Cartesian expression in (5).

The utility of saturation potential vorticity differs from that of Ertel's dry potential vorticity: $P^{*}$ is not materially conserved in unsaturated displacements, but it shows the relationship between gradients of $\theta_{e}^{*}$ and vortex lines. Because the absolute vorticity vector points parallel to isolines of angular momentum (cf. Frisius 2005), $P^{*}$ measures how well $\theta_{e}^{*}$ and angular momentum surfaces are aligned. Wherever convection has established a moist-adiabatic lapse rate (characterized by constant $\theta_{e}^{*}$ ) along angular momentum surfaces, $P^{*}$ vanishes. This makes it well suited to analyze the thermal stratification of air masses. To simplify our analysis, we define a modified saturation potential vorticity

$$
P_{+}^{*}=\operatorname{sign}(f) P^{*},
$$

whose sign has the same meaning in both hemispheres. [Similarly, $P_{+}$will refer to $P$ multiplied by $\operatorname{sign}(f)$.] In this form, wherever $P_{+}^{*}<0$, lapse rates along angular momentum surfaces are greater than moist adiabatic (e.g., dry-adiabatic regions and conditionally unstable air masses); wherever $P_{+}^{*}>0$, lapse rates along angular momentum surfaces are less than moist adiabatic (i.e., stable to all convection); wherever $P_{+}^{*} \approx 0$, the air is approximately neutral to moist convection. This simple diagnostic can be easily calculated and used to assess static stability.

Structurally, $P_{+}^{*}$ and $P_{+}$have many similarities, but the deviations of $P_{+}^{*}$ from the conventional $P_{+}$are criti- cal for our analysis. We computed $P_{+}$and $P_{+}^{*}$ for each day in January between 1970 and 2004, and Fig. 2 shows the zonal and monthly mean values of these quantities. While the two quantities are similar in the stratosphere and in polar latitudes of the troposphere, they differ substantially in the troposphere south of this region. Note the sharp transition from low to high values of $P_{+}^{*}$ in the extratropics, and the extensive region with values near zero. This sharp boundary is common, and as a result we can choose an arbitrary threshold in this window of rapid transition to divide air masses with nearzero values from those with higher values. Hoskins et al. (1985) show that tropospheric values of $P_{+}$are smaller than 1.5 PVU (with $1 \mathrm{PVU}=10^{-6} \mathrm{~K} \mathrm{~m}^{2} \mathrm{~kg}^{-1} \mathrm{~s}^{-1}$ ), and this value is used to identify the extratropical tropopause. We choose the criterion $P_{+}^{*}<0.15 \mathrm{PVU}$, an order of magnitude smaller than that used to define the tropopause, to identify air masses with near-zero $P_{+}^{*}$ values. The threshold is arbitrary, but it was chosen to be in the window of sharp transition that separates air with near-zero $P_{+}^{*}$ from air with larger values of $P_{+}^{*}$, as seen in Fig. 2b. Our analysis is relatively insensitive to the precise threshold selected, so long as it is between about 0.05 and 0.2 PVU.

As proposed by Emanuel (2008), $P_{+}^{*}$ can be used to classify air masses. Wherever $P_{+}^{*}$ is approximately zero, saturation entropy is nearly constant on isosurfaces of absolute angular momentum, and the thermal stratification is likely to have been convectively adjusted; this state is common throughout the Tropics and sometimes at higher latitudes, too. At the tropopause, $P_{+}^{*}$ is ap- 
proximately equal to $P_{+}$, as $\theta_{e}^{*}-\theta$ is small at low temperatures; stratospheric air masses are characterized by large values of $P_{+}^{*} \approx P_{+}$. In polar air masses with a stable stratification, $P_{+}^{*}$ is large and approximately equal to $P_{+}$. In boundary layers and over deserts, where dry-adiabatic lapse rates are maintained, $P_{+}^{*}$ may become negative. We focus on the first of these groups: air masses in which moist-adiabatic lapse rates are established along surfaces of angular momentum such that $P_{+}^{*}$ is nearly zero. We assess where and when such air masses occur.

To develop this climatology, we calculated the saturation potential vorticity and other variables presented in this paper from a subset of the NCEP-NCAR reanalysis data (Kalnay et al. 1996). We used dailyaveraged data between 1970 and 2004 from the NCEPNCAR reanalysis project and calculated $P_{+}^{*}$ at each horizontal grid point and pressure level for each day of the 35 -yr period. We used data on 17 pressure levels with $2.5^{\circ}$ latitude by $2.5^{\circ}$ longitude horizontal resolution. Reanalysis data include information gathered from radiosondes, and there has been some concern about the quality of such data (see, e.g., Sherwood et al. 2005); however, radiosonde biases likely affect trends more strongly than the mean state, which is of primary interest here. In section 6, we compare some of our results to those obtained using the North American Regional Reanalysis (Mesinger et al. 2006), which is a higher-resolution regional dataset.

\section{Seasonal extremes}

We now examine the mean state of $P_{+}^{*}$ in different regions and at different times of the year. We computed $\theta_{e}^{*}$ and $P_{+}^{*}$ for each of the January and July days between 1970 and 2004 and averaged the values to form a monthly mean; the data presented in this section are monthly mean values. In the Tropics, where the role of convection on the thermal stratification is well established, $P_{+}^{*}$ assumes a value near zero universally. Over tropical land and oceans and throughout the year, the thermal stratification is nearly moist adiabatic. This diagnostic confirms the findings of earlier analyses, such as that of Xu and Emanuel (1989). Our principal interest is to identify the times and locations in the extratropics where convectively neutral thermal stratifications occur. We proceed first by looking at temporal averages along the cross sections of longitude and latitude shown in Fig. 3.

\section{a. Cross sections in January}

Figure 4 shows mean values of $\theta_{e}^{*}$ and $P_{+}^{*}$ in January along several longitudinal cross sections. Values of $P_{+}^{*}$

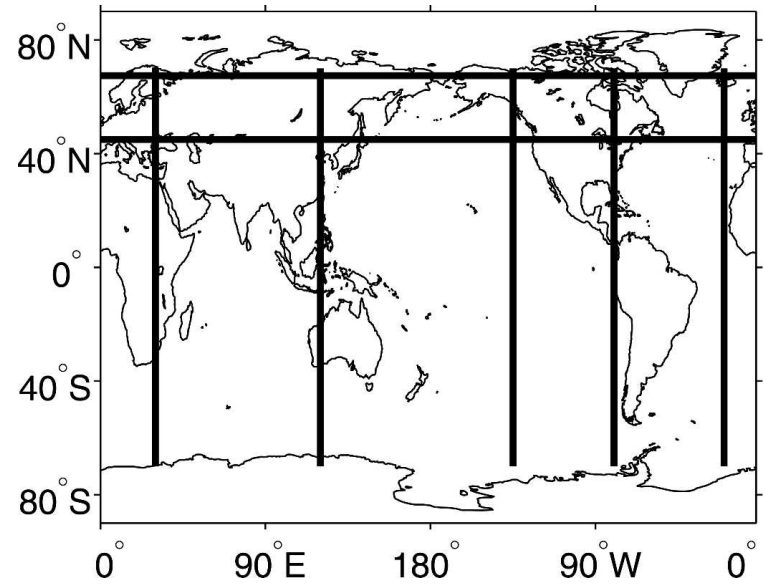

FIG. 3. A map of the locations of cross sections plotted in Figs. 4-7. Longitudinal cross sections are shown between $70^{\circ} \mathrm{S}$ and $70^{\circ} \mathrm{N}$.

that are near zero $\left(\left|P_{+}^{*}\right|<0.15\right.$ PVU $)$ are shaded in light gray, and values of $P_{+}^{*}$ that are significantly less than zero $\left(P_{+}^{*}<-0.15\right.$ PVU) are shaded in dark gray. The 1.5-PVU $P_{+}^{*}$ contour, indicating the tropopause in the extratropics, is drawn with a thick black line. As discussed earlier, the threshold between stable and convectively neutral air masses was chosen to be the 0.15 PVU $P_{+}^{*}$ surface, but the boundary between air masses is not sensitive to this choice because of the rapidity with which $P_{+}^{*}$ increases outside of convectively neutral air masses (see Fig. 2b). In particular, choosing a $P_{+}^{*}$ threshold value that is proportional to the Coriolis parameter $f$ and hence is latitude dependent does not substantially affect our results.

Convection is important well into the midlatitudes along the oceanic meridians (Figs. 4a,b show sections through the eastern Atlantic and eastern Pacific). Over the eastern Atlantic and Pacific Oceans in January, the thermal stratification is neutral to moist convection up to about $500 \mathrm{hPa}$ to at least $55^{\circ}-65^{\circ} \mathrm{N}$. (In the western part of the basins, just east of large continents, convectively neutral air masses do not extend as far north as in the eastern part of the basins; we shall examine this more closely in section 4.) The saturation potential vorticity $P_{+}^{*}$ is sometimes near zero poleward of this latitude over the winter oceans, but this is not evident in the mean fields because stable, high- $P_{+}^{*}$ Arctic air masses are present on some days as well.

Over continents, however, the thermal stratification appears to be more stable during winter. Figures $4 \mathrm{c}-\mathrm{e}$ show cross sections along $30^{\circ} \mathrm{E}, 120^{\circ} \mathrm{E}$, and $80^{\circ} \mathrm{W}$. As shown in Fig. 3, these run through Africa and Europe, Australia to eastern China and Russia, and the South American Pacific coast to eastern North America. Mid- 
(a) $P_{+}^{*}$ and $\theta_{e}^{*}$ along $20^{\circ} \mathrm{W}$

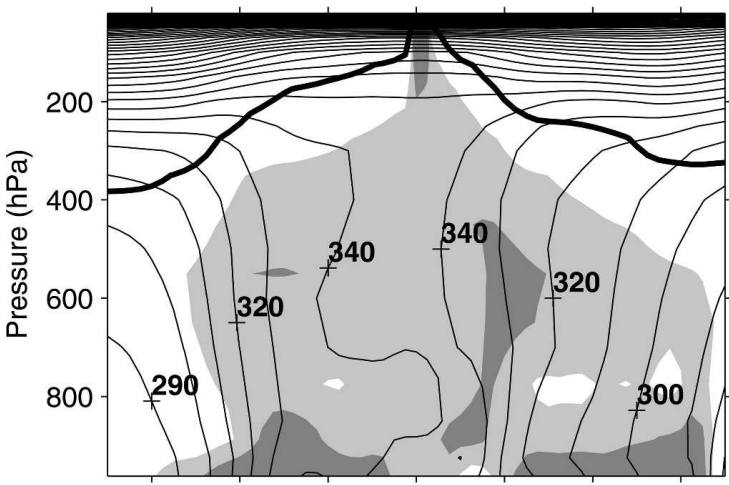

(c) $\mathrm{P}_{+}^{*}$ and $\theta_{\mathrm{e}}^{*}$ along $30^{\circ} \mathrm{E}$

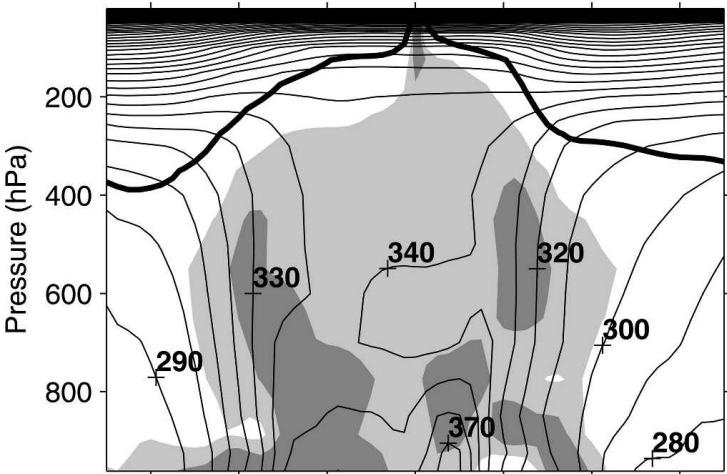

(e) $\mathrm{P}_{+}^{*}$ and $\theta_{\mathrm{e}}^{*}$ along $80^{\circ} \mathrm{W}$

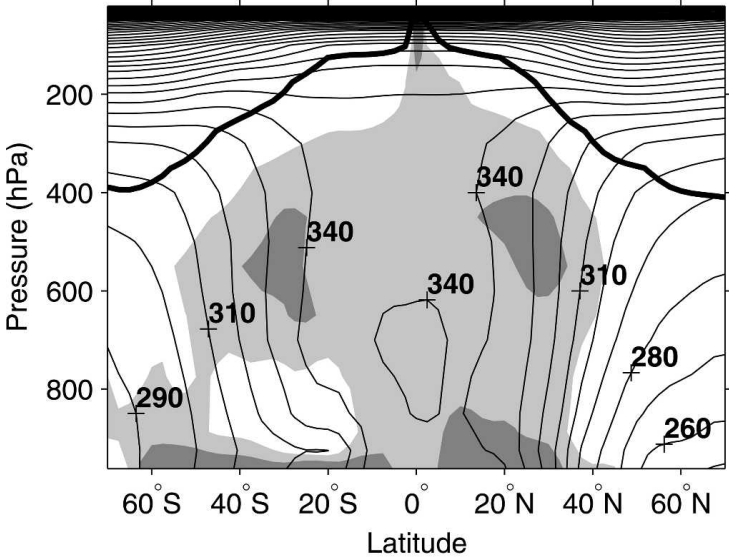

(b) $\mathrm{P}_{+}^{\star}$ and $\theta_{\mathrm{e}}^{\star}$ along $135^{\circ} \mathrm{W}$

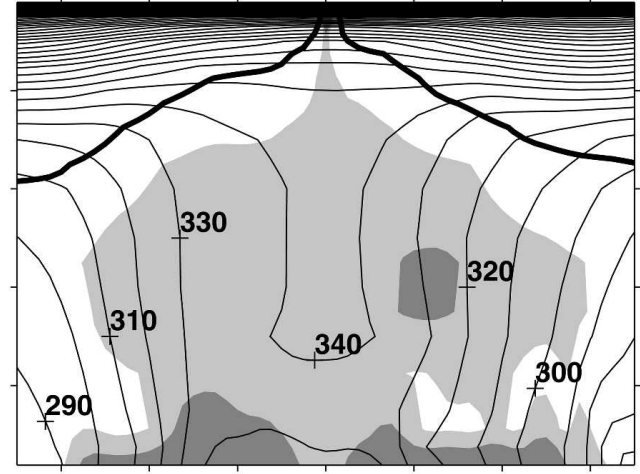

(d) $P_{+}^{*}$ and $\theta_{e}^{*}$ along $120^{\circ} \mathrm{E}$

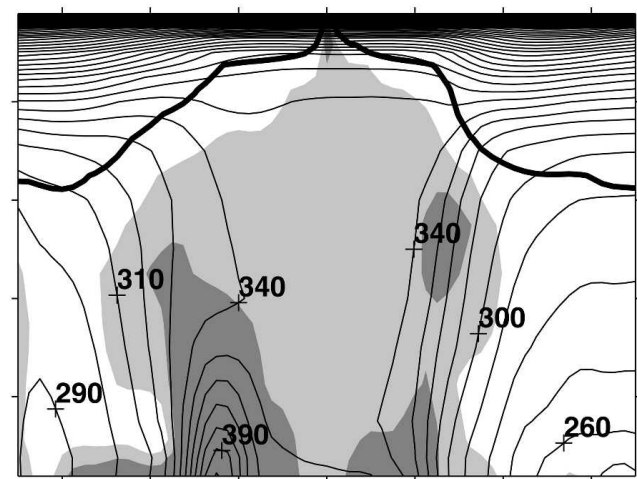

(f) Zonal mean of $\mathrm{P}_{+}^{*}$ and $\theta_{\mathrm{e}}^{*}$

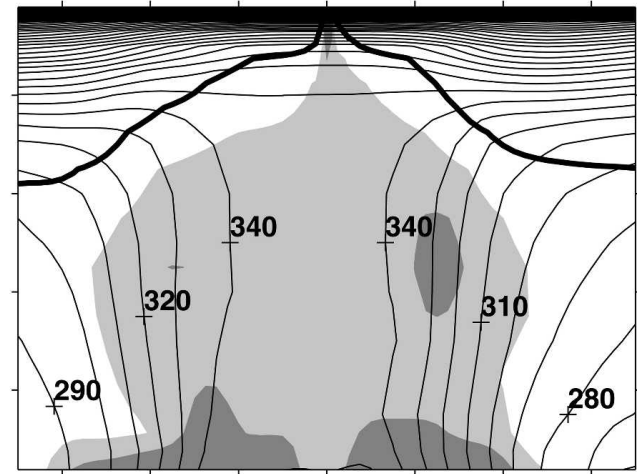

$60^{\circ} \mathrm{S} 40^{\circ} \mathrm{S} 20^{\circ} \mathrm{S} \quad 0^{\circ} \quad 20^{\circ} \mathrm{N} \quad 40^{\circ} \mathrm{N} \quad 60^{\circ} \mathrm{N}$

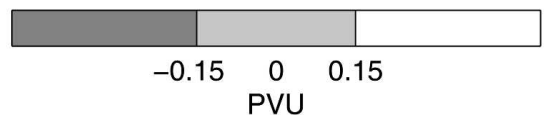

FIG. 4. January averages of $P_{+}^{*}$ (shaded) and $\theta_{e}^{*}$ (contours) equatorward of $70^{\circ}$ latitude along (a) $20^{\circ} \mathrm{W}$, (b) $135^{\circ} \mathrm{W}$, (c) $30^{\circ} \mathrm{E}$, (d) $120^{\circ} \mathrm{E}$, (e) $80^{\circ} \mathrm{W}$, and (f) in the zonal mean. The 1.5 -PVU contour is drawn with a thick black line.

latitudes over all Northern Hemisphere continents are stable to moist convection in January, with near-zero $P_{+}^{*}$ air confined to latitudes equatorward of $30^{\circ}$ or $40^{\circ}$ N. In the Southern Hemisphere (summer), convec- tively neutral or moist-unstable air masses can be found from the Tropics to about $50^{\circ} \mathrm{S}$ independent of longitude. Note that $\theta_{e}^{*}$ decreases with altitude over desert regions of western Australia (Fig. 4d), which leads to 


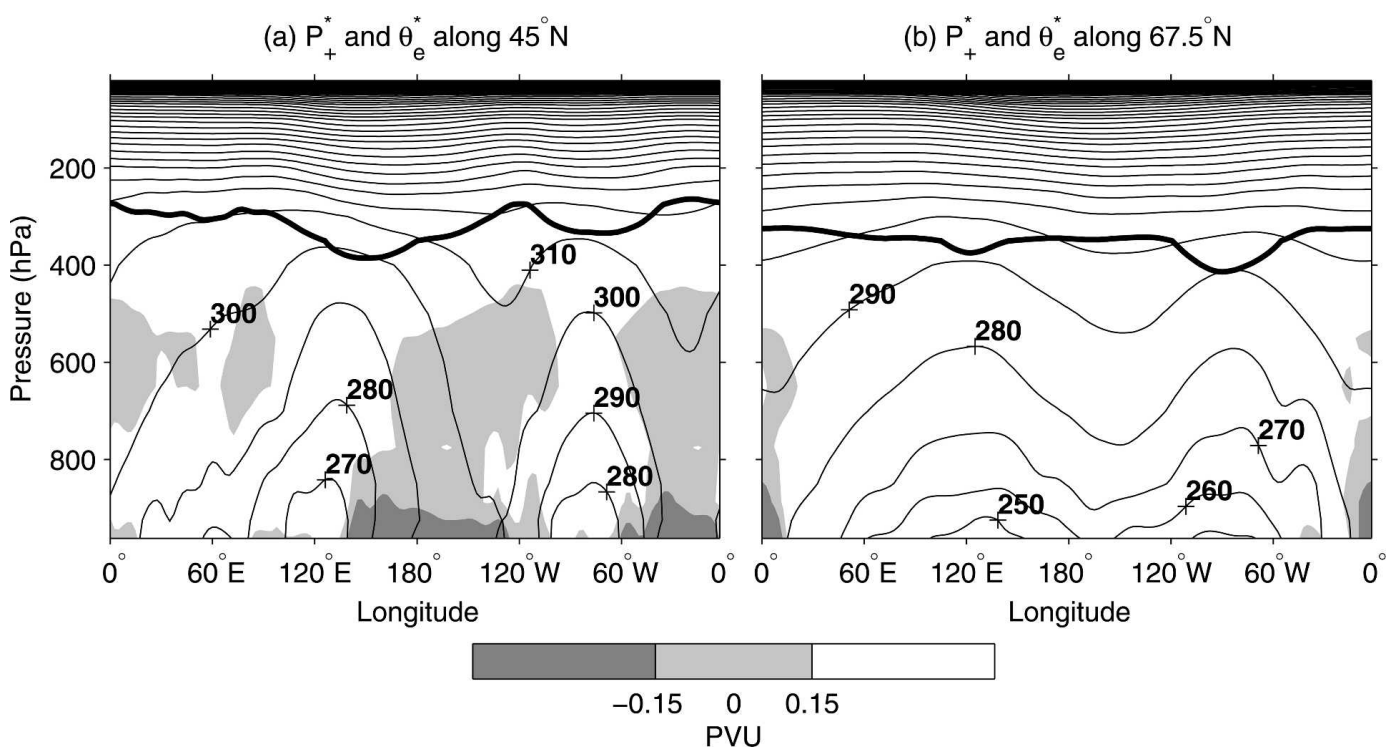

FIG. 5. Same as in Fig. 4, but along latitude circles at (a) $45^{\circ}$ and (b) $67.5^{\circ} \mathrm{N}$.

negative values of $P_{+}^{*}$. This is common over deserts in both hemispheres, particularly during summer months, when the hot, dry air often exhibits a dry-adiabatic thermal stratification. Below about $900 \mathrm{hPa}$, boundary layer air is usually well mixed with $\theta$ nearly constant with height. These regions have negative values of $P_{+}^{*}$ as well. ${ }^{3}$

Thus, there is a good deal of variability in the poleward extent of convectively neutral air. Much of this structure is lost by examining only the zonal mean, which is shown in Fig. 4f. During winter, air masses over continents, particularly over their eastern sides, tend to be more stable than maritime air masses at the same latitude. Cross sections taken along a latitude circle reveal this division. Figure 5a shows variations of $P_{+}^{*}$ along $45^{\circ} \mathrm{N}$ in January. Over both the Pacific and Atlantic Oceans, the thermal stratification is neutral to moist convection through a deep layer of the troposphere. Over continents, the intrusion of Arctic air masses can be seen from the lower $\theta_{e}^{*}$ values near the surface and a more stable thermal stratification. The thermal stratification is convectively neutral north of this latitude on occasion in January but generally not in the time mean. Signs of convectively neutral air can be seen over both land and oceans from $50^{\circ} \mathrm{S}$ to $30^{\circ} \mathrm{N}$ in January (Fig. 4). Even north of $30^{\circ} \mathrm{N}$, convectively neutral air seems to dominate maritime air masses to $50^{\circ} \mathrm{N}$, and on occasion even farther poleward. Some low- $P$ *

\footnotetext{
${ }^{3}$ Not all regions in which $P_{+}^{*}<-0.15$ PVU are characterized by a dry-adiabatic lapse rate, but wherever dry-adiabatic lapse rates are found in the mid- and low latitudes, $P_{+}^{*}$ will be negative. In very cold air, dry and moist adiabats converge.
}

air can be regularly found as far north as the Norwegian Sea, as shown in Fig. 5b.

\section{b. Cross sections in July}

During boreal summer, low values of $P_{+}^{*}$ are common throughout the Northern Hemisphere. Figure 6 shows cross sections along oceanic and continental longitudes for July. Over the eastern Atlantic (Fig. 6a) and eastern Pacific (Fig. 6b), convectively neutral air masses penetrate about as far into the extratropics as they did in January. Some high- $\theta_{e}^{*}$ air and dry-adiabatic air masses, which are indicated by regions of $P_{+}^{*}<0$, can be found just east of Senegal along $20^{\circ} \mathrm{W}$ at around $20^{\circ} \mathrm{N}$; this air shares many characteristics with Saharan air masses and is presumably advected offshore by the prevailing low-levels winds. In both the eastern Pacific and eastern Atlantic, the thermal stratification is stable in the extratropical lower troposphere; convectively neutral air dominates the midtroposphere to $50^{\circ} \mathrm{N}$.

Cross sections over continental locations in the Northern Hemisphere indicate that convectively neutral air masses can be routinely found during summer. Over subtropical deserts, very high values of $\theta_{e}^{*}$ are common in the lower troposphere and coincide with regions of $P_{+}^{*}<0$ where dry convection is common. Figure $6 \mathrm{c}$, taken along $30^{\circ} \mathrm{E}$ in July, shows an example of this through Sudan and Egypt, where $\theta_{e}^{*}$ exceeds $400 \mathrm{~K}$. This cross section also shows that convectively neutral or unstable air masses can be found all the way to the Arctic Ocean, with stable air confined to latitudes poleward of $70^{\circ} \mathrm{N}$. Convectively neutral or unstable air masses prevail over Asia all the way to the 
(a) $\mathrm{P}_{+}^{*}$ and $\theta_{e}^{*}$ along $20^{\circ} \mathrm{W}$

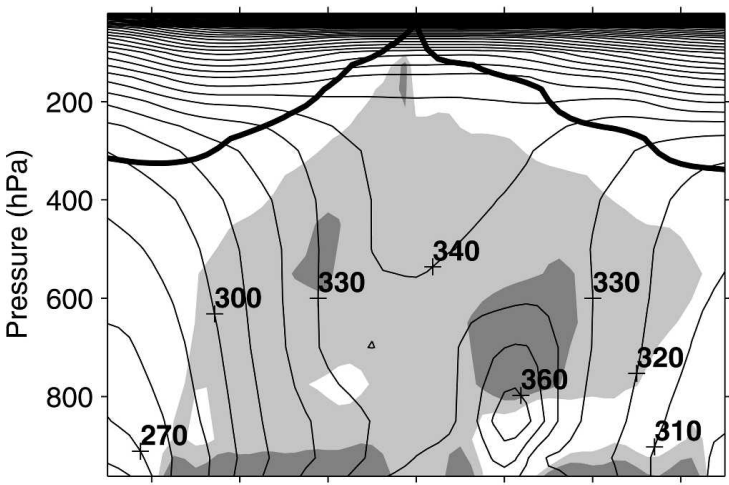

(c) $\mathrm{P}_{+}^{*}$ and $\theta_{\mathrm{e}}^{*}$ along $30^{\circ} \mathrm{E}$

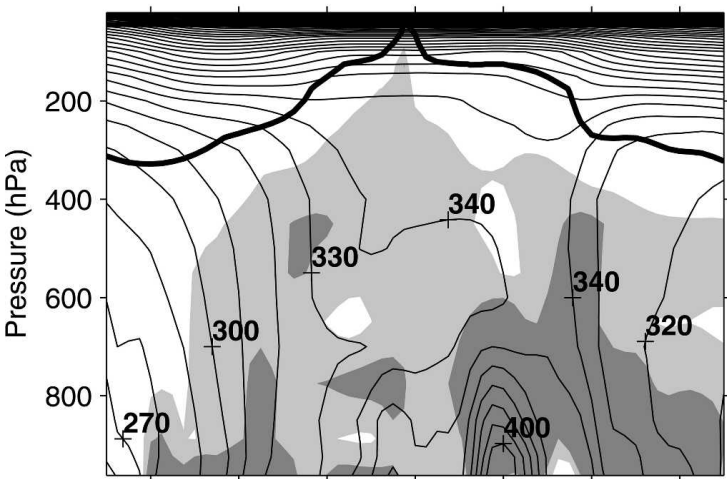

(e) $P_{+}^{*}$ and $\theta_{e}^{*}$ along $80^{\circ} \mathrm{W}$

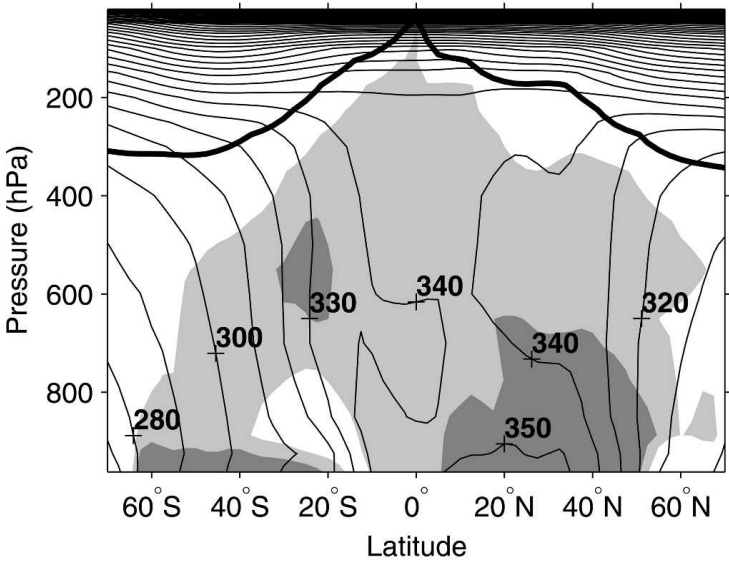

(b) $\mathrm{P}_{+}^{\star}$ and $\theta_{\mathrm{e}}^{\star}$ along $135^{\circ} \mathrm{W}$

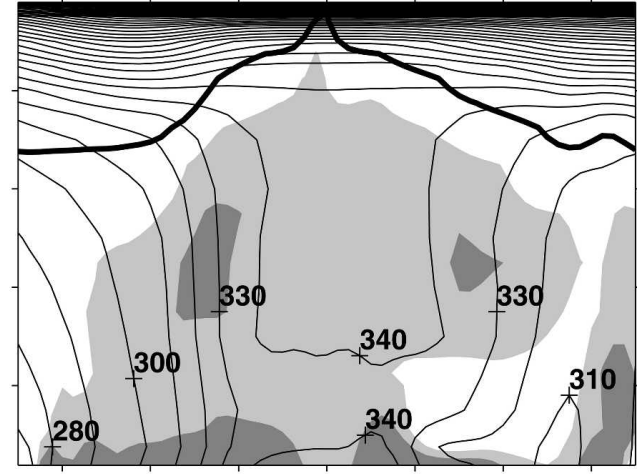

(d) $P_{+}^{*}$ and $\theta_{e}^{*}$ along $120^{\circ} \mathrm{E}$

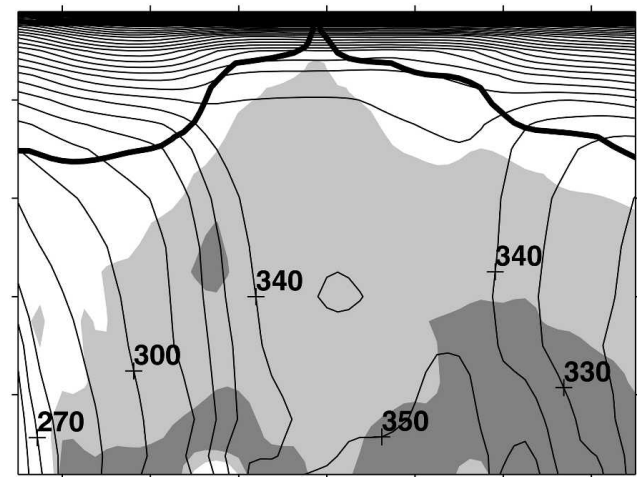

(f) Zonal mean of $\mathrm{P}_{+}^{*}$ and $\theta_{\mathrm{e}}^{*}$

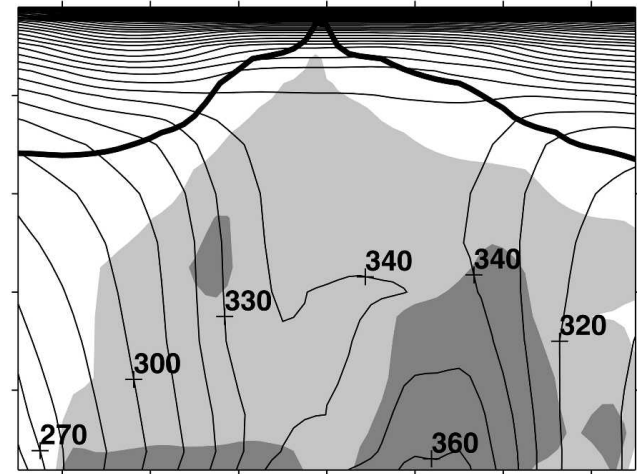

$60^{\circ} \mathrm{S} 40^{\circ} \mathrm{S} 20^{\circ} \mathrm{S} \quad 0^{\circ} \quad 20^{\circ} \mathrm{N} \quad 40^{\circ} \mathrm{N} \quad 60^{\circ} \mathrm{N}$ Latitude

\section{$-0.15 \underset{\text { PVU }}{0} 0.15$}

FIG. 6. Same as in Fig. 4, but for July.

Arctic coast (Fig. 6d) and to the shoreline of Hudson Bay over eastern North America (Fig. 6e). The zonal mean in Fig. 6f also shows a northward expansion of convectively neutral or unstable air, although much of the regional structure is lost with this averaging.

Figure $7 \mathrm{a}$ shows a cross section along the latitude circle $45^{\circ} \mathrm{N}$. Convectively neutral or unstable air masses can be found along much of this latitude circle. In contrast to Fig. 5a, which was taken along the same latitude circle in January, the stratification is convectively neutral or unstable through the depth of the troposphere over the continents in July. Some stable air can be seen 


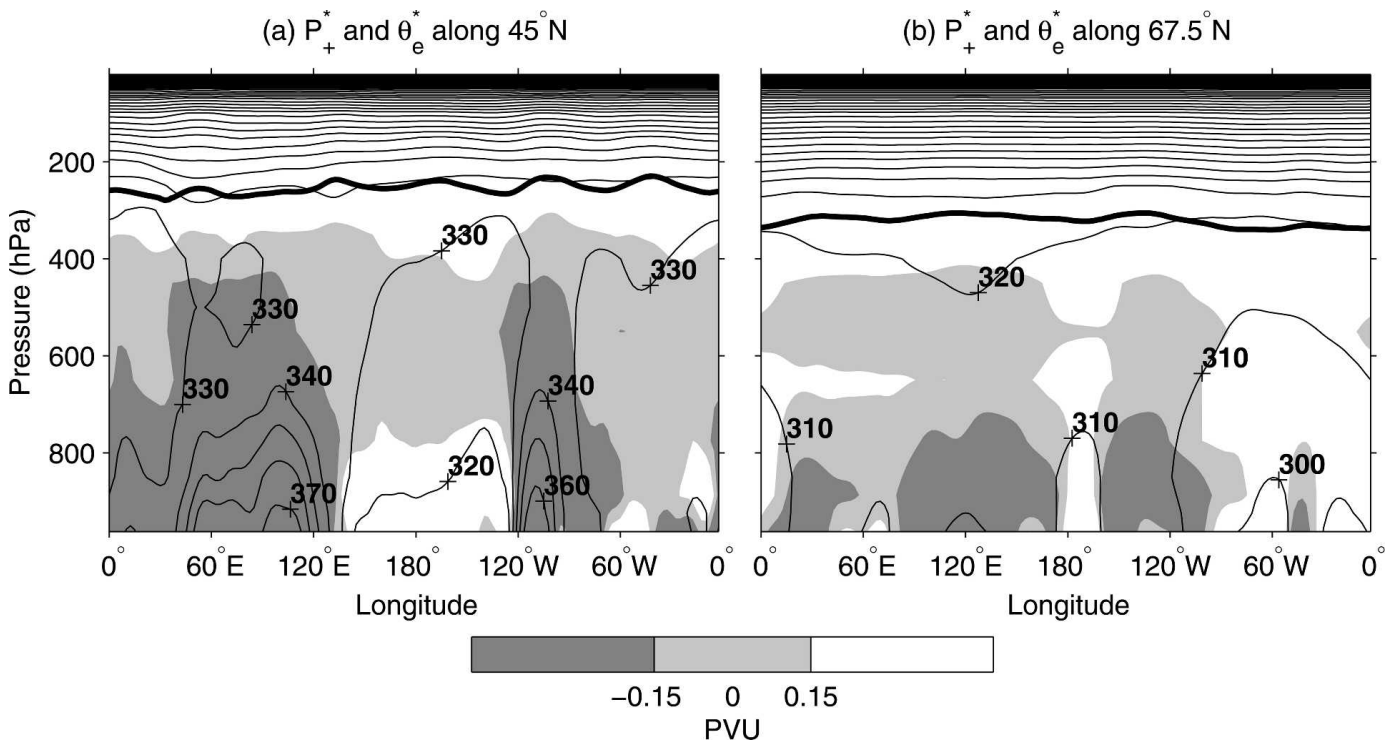

FIG. 7. Same as in Fig. 5, but for July.

in the lower troposphere over the oceans, particularly over the Pacific Ocean. Even north of the Arctic Circle, as shown at $67.5^{\circ} \mathrm{N}$ in Fig. $7 \mathrm{~b}$, the air is, on average, convectively neutral or unstable across Scandinavia, Siberia, and Alaska.

It appears that summertime convection is important over the continents. Convectively neutral or unstable air is common in July throughout the Northern Hemisphere midlatitudes. Stable air can be found only poleward of the Arctic Circle. Of course, having a value of $P_{+}^{*}>0$ in the mean state does not mean that convection is always unimportant. We turn to analysis of the temporal variations in the next section.

\section{Temporal variations}

The results presented in the previous section show that convectively neutral air masses can be found routinely in the extratropics. We now examine the frequency with which convectively neutral air masses occur. Regions in which the thermal stratification is controlled by moist convection at some times and stabilized by eddies at others will acquire temporally averaged values $P_{+}^{*}>0$. Such regions will lack the signature of convectively neutral air in the mean fields.

We formed an average annual cycle of $P_{+}^{*}$ by averaging the daily values for each calendar day over the 35 -yr sample to produce a 365 -day time series. ${ }^{4} \mathrm{We}$

\footnotetext{
${ }^{4}$ Data from 29 February were excluded.
}

then located the northernmost latitude at which $P_{+}^{*}<$ 0.15 PVU on each meridian for each day of the averaged time series. To avoid isolated pockets of low- $P_{+}^{*}$ air, we repeated this analysis three additional times, but adding the increasingly stringent requirement that $P_{+}^{*}<0.15 \mathrm{PVU}$ for at least the next $5^{\circ}, 7.5^{\circ}$, and $10^{\circ}$ latitude south of the first occurrence. To produce Fig. 8, we used data from the most restrictive analysis, in which the condition must hold for at least $10^{\circ}$ latitude south of the location plotted. We applied a 10-day running mean to smooth the plot. The other analyses, which required that the condition $P_{+}^{*}<0.15$ PVU hold for smaller distances to the south, are qualitatively similar to the data presented in Fig. 8, but they are noisier as smaller, isolated pockets of convectively neutral air are not filtered out. ${ }^{5}$

In the zonal mean, shown in Fig. 8a, the Northern Hemisphere is routinely convectively neutral to $40^{\circ} \mathrm{N}$ through most of troposphere. But during the warmer half of the year, from April to October, convectively neutral air can also be found at higher latitudes. During summer, the northernmost occurrence of convectively neutral air lays poleward of $70^{\circ} \mathrm{N}$. Several of the cross sections presented in the last section showed convec-

\footnotetext{
${ }^{5}$ The analysis is also sensitive to the order of the calculation. If the northern extent of convectively neutral air is first identified along each meridian for each day of the 35-yr sample and then averaged to form an annual cycle (as opposed to first averaging $\left.P_{+}^{*}\right)$, the northern extent appears as much as $10^{\circ}$ farther north than shown in Fig. 8 during much of the winter. Qualitatively, however, the patterns are not different.
} 
(a) Zonal mean
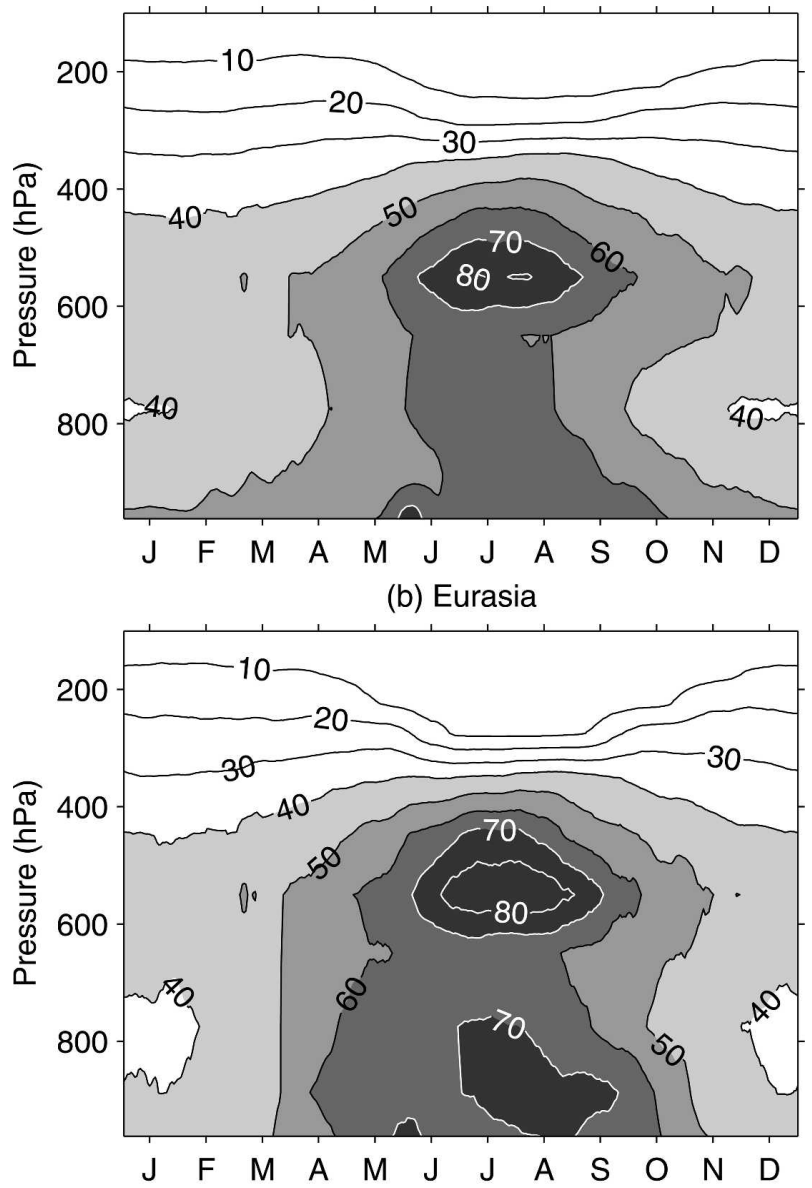

(c) Atlantic

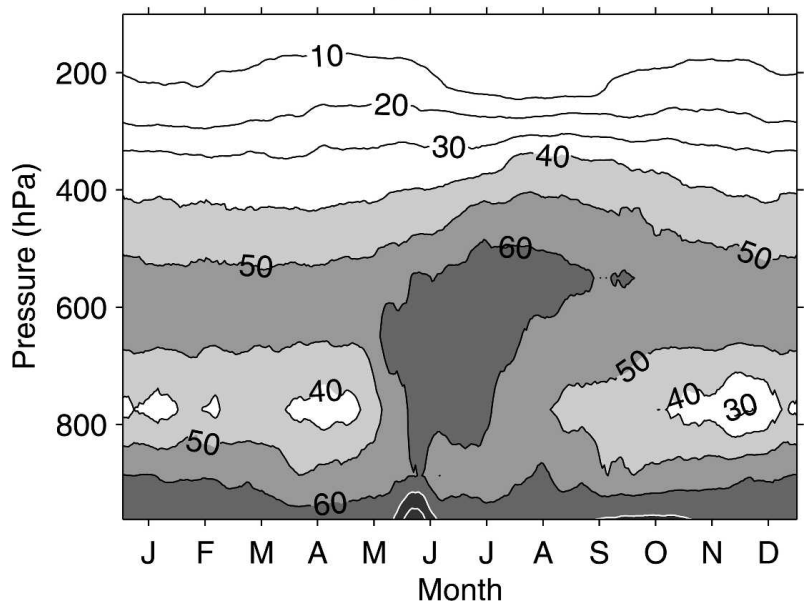

FIG. 8. Northernmost latitude at which $P_{+}^{*}<0.15$ PVU in (a) the zonal mean, (b) over Eurasia (between $5^{\circ}$ and $135^{\circ} \mathrm{E}$ ), and (c) over the Atlantic (between $60^{\circ}$ and $15^{\circ} \mathrm{W}$ ). Data were smoothed with a 10-day running mean; see section 4 for further details. tively neutral air routinely occurring in high latitudes in July. Much of this seasonal variation comes from continental air masses, as can be seen from Fig. 8b, which shows the northernmost extent of low- $P_{+}^{*}$ air over Europe and Asia $\left(5^{\circ}-135^{\circ} \mathrm{E}\right)$. This continental seasonal variation, which can also be found over North America, dominates the seasonal increase seen in the zonal mean. Over the oceans, the seasonal variations are smaller, as can be see from Fig. $8 \mathrm{c}$, which shows the northernmost extent of low- $P_{+}^{*}$ air over the Atlantic $\left(60^{\circ}-15^{\circ} \mathrm{W}\right)$. Here and over the eastern Pacific, convectively neutral air can be routinely found to $50^{\circ} \mathrm{N}$ near $500 \mathrm{hPa}$. In June and July, convectively neutral air over Greenland and Iceland pull the northernmost latitude poleward of $60^{\circ} \mathrm{N}$.

One interesting feature that can be seen in all three panels is that a layer of more stable air resides between 700 and $800 \mathrm{hPa}$. This is most common during the winter months, but it can be found over the subtropical oceans year-round, where it is likely a signature of the trade inversion. The stable layer observed in the lower troposphere in the mid- and high latitudes may be a signature of eddy influences. Schneider and Walker (2006) found in simulations with an idealized general circulation model that eddies stabilize the lower troposphere most effectively.

Figure 9 shows the fraction of days in Januarys and Julys for which $P_{+}^{*}<0.15$ PVU at three different pressure levels. At $350 \mathrm{hPa}$, low- $P_{+}^{*}$ air is largely confined to the Tropics, where the troposphere is deeper, but even at this pressure level continental locations of the Northern Hemisphere do have areas neutral to moist convection a significant fraction of the time during summer (Fig. 9b). In the midtroposphere in January (Fig. 9c), the distribution of landmasses is imprinted on the static stability of air at northern latitudes, with Siberia and eastern Canada dominated by stable air, and intrusions of convectively neutral air common on the western side of the continents. The oceanic storm tracks in the Atlantic and Pacific are lines of demarcation between regions that are frequently neutral to moist convection and those largely stable to it.

In the midtroposphere in July (Fig. 9d), low- $P_{+}^{*}$ air can be found nearly throughout the Northern Hemisphere a substantial fraction of the time. While the analysis in section 3 shows that regions with small or negative values of $P_{+}^{*}$ can be found over continents in the temporal mean, here we see that air at all longitudes is neutral (or conditionally unstable) to moist convection a substantial fraction of the time all the way into the Arctic Ocean. Convectively neutral air is common throughout the Northern Hemisphere during summer, over both land and sea. 
(a) January $350 \mathrm{hPa}$

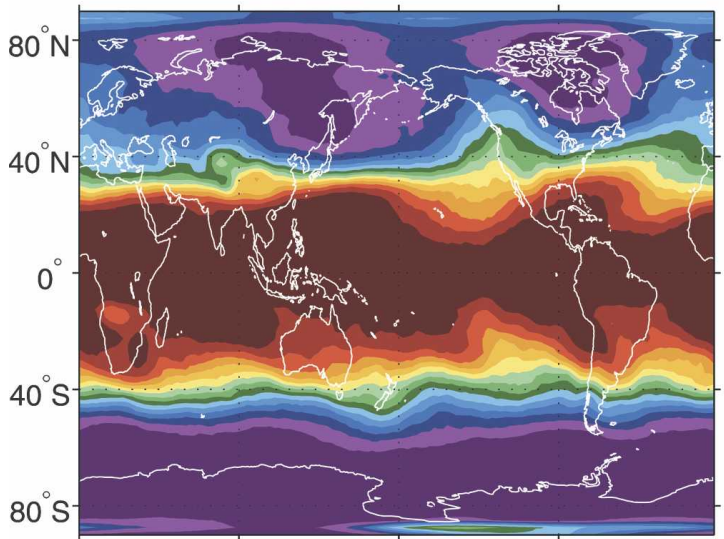

(c) January $550 \mathrm{hPa}$

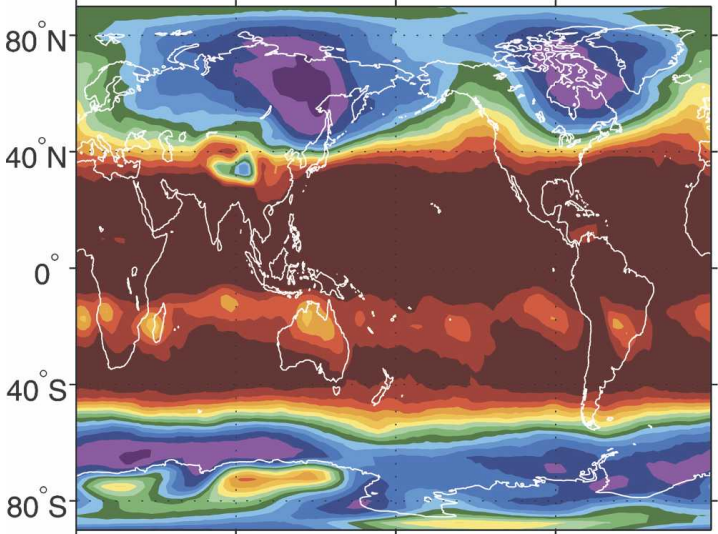

(e) January $775 \mathrm{hPa}$

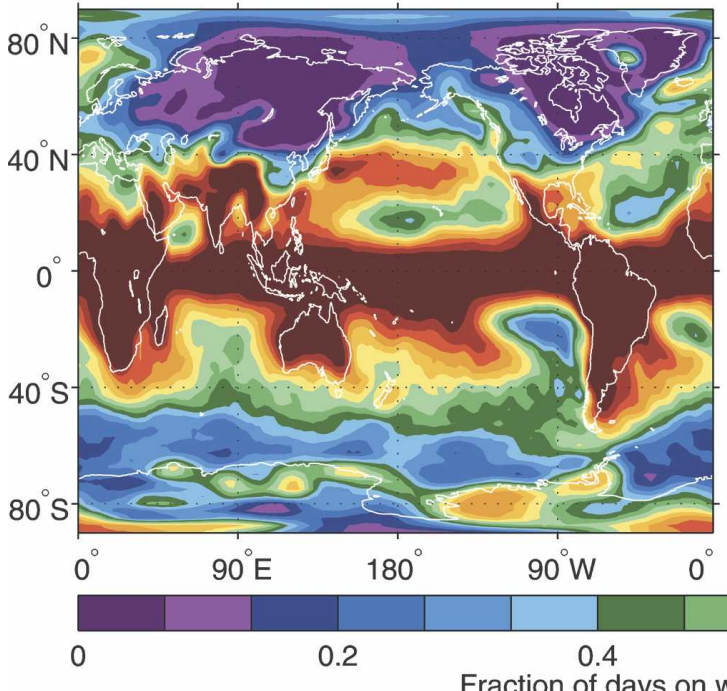

Fraction of days on which $\mathrm{P}_{+}{ }^{*}<0.15 \mathrm{PVU}$

(b) July $350 \mathrm{hPa}$

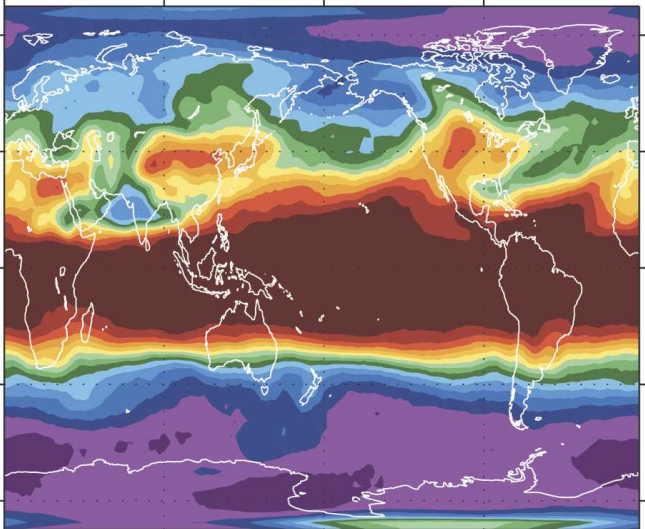

(d) July $550 \mathrm{hPa}$

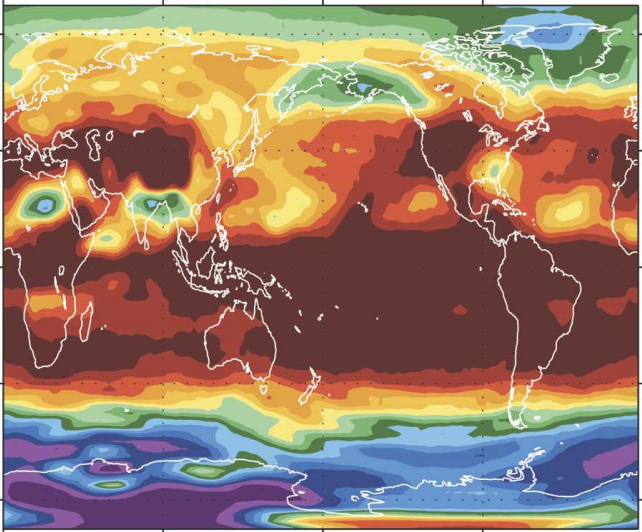

(f) July $775 \mathrm{hPa}$

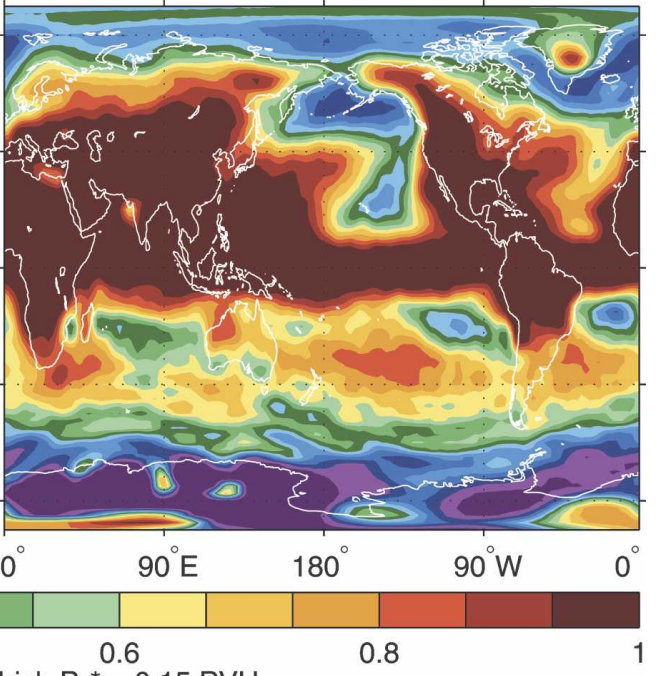
FIG. 9. Fraction of the days $(1970-2004)$ on which $P_{+}^{*}<0.15 \mathrm{PVU}$ (a) in January at $350 \mathrm{hPa}$, (b) in July at 350
$\mathrm{hPa}$, (c) in January at $550 \mathrm{hPa}$, (d) in July at $550 \mathrm{hPa},(\mathrm{e})$ in January at $775 \mathrm{hPa}$, and (f) in July at $775 \mathrm{hPa}$. 
In the lower troposphere, there are signs of convectively stable stratification in the mid- and high latitudes over continents in winter and over oceans year-round. Stable, high- $P_{+}^{*}$ polar air sits across the Arctic and much of Asia and North America in January. But most interesting are the winter storm tracks, which feature more frequent low- $P *$ air over the oceans than can be found on either side of them. This is seen in the Pacific and North Atlantic in Fig. 9e, and in the Southern Hemisphere winter storm tracks east of Australia in July in Fig. 9f.

\section{Relative importance of slantwise convection}

We have assessed neutrality of the thermal stratification with respect to slantwise convection; however, if areas of slantwise-convective neutrality (as distinct from vertical-convective neutrality) are rare, an analysis using vertical gradients of saturation equivalent potential temperature $\theta_{e}^{*}$ in place of $P^{*}$ would suffice. The dominant term of $P_{+}^{*}$ in the extratropics involves vertical gradients of $\theta_{e}^{*}$ alone $\left(-g f \partial_{p} \theta_{e}^{*}\right)$, and in regions with vertical lapse rates that are nearly moist adiabatic, both it and $P^{*}$ will be near zero. Figure 10 is an analog of Fig. 9; it shows the number of days on which $\partial_{p} \theta_{e}^{*}$ is approximately zero. (To define a compatible threshold, we used the value of $\partial_{p} \theta_{e}^{*}$ that would make $-g f \partial_{p} \theta_{e}^{*}$ the dominant term of $P^{*}$, equal $0.15 \mathrm{PVU}$ at $30^{\circ} \mathrm{N}$. Thus, Fig. 10 shows the number of days in which $-g \Omega \partial_{p} \theta_{e}^{*}<$ 0.15 PVU.)

Figure 10 shows that vertical moist-adiabatic lapse rates are less common, though they appear to be prevalent during summer over continents in the lower troposphere. Among the most striking changes from Fig. 9 is the reduced frequency of occurrence of convectively neutral air, especially in strongly baroclinic regions such as the winter storm tracks over oceans. Including the horizontal terms in (5) is important in many parts of the troposphere, as the threshold used for Fig. 10 misses a significant fraction of the days with a nearly convectively neutral profile. Generally, Figs. 9 and 10 differ less in the summer hemisphere than in the winter one. Slantwise convection appears especially important to consider over the winter oceans.

Another interesting feature of Fig. 10 is the inability of this threshold to capture the convectively neutral lapse rates in parts of the deep Tropics, especially in the midtroposphere. Rather than indicating that slantwise convection is important at these latitudes, however, the lack of condensate loading could be responsible. Xu and Emanuel (1989) pointed out that soundings in the deep Tropics are generally neutral to moist convection, but that the effects of condensate loading must be in- cluded to see this clearly. We have not included such effects here, and a midtropospheric minimum of $\theta_{e}^{*}$ in the deep Tropics can be seen in several of the cross sections shown in Fig. 4.

\section{Discussion and conclusions}

The results of our analysis suggest that vertical convection or slantwise convection may be important for the maintenance of the thermal stratification at least in parts of the extratropics. In the Tropics, where the role of moist convection in maintaining the thermal stratification is well established (Sarachik 1985; Xu and Emanuel 1989), air masses with low values of $P_{+}^{*}$ are omnipresent. Our key result is that regions neutral to moist convection along angular momentum surfaces are common in the extratropics. For example, air masses neutral with respect to vertical or slantwise convection are common over midlatitude continents in both hemispheres in summer and in storm tracks over oceans in winter.

Variations of our analysis in which we used a threshold for low values of $-\partial_{p} \theta_{e}^{*}$ in lieu of the full definition of $P_{+}^{*}$ revealed that, in mid- and high latitudes, slantwise rather than vertical convection may contribute to the maintenance of the thermal stratification, particularly over the oceans in the lower and midtroposphere. We found that the thermal stratification is more often close to slantwise-convective neutrality than to verticalconvective neutrality, especially in strongly baroclinic regions such as the North Pacific storm track during January. This is consistent with the findings of Emanuel (1988), who identified slantwise-convective neutral states in the ascent regions of baroclinic cyclones.

We chose the NCEP-NCAR reanalysis dataset because of its global coverage, but to test to what extent our results are sensitive to the coarse resolution of the reanalysis dataset (particularly in the vertical), we compared our results to those calculated from the highresolution North American Regional Reanalysis (NARR; Mesinger et al. 2006), which has 29 tropospheric pressure levels and a horizontal resolution of 32 $\mathrm{km}$. We linearly interpolated (in the horizontal) the daily-averaged data between 1979 and 2004 to a grid with $0.5^{\circ}$ latitude by $0.5^{\circ}$ longitude resolution and calculated $P_{+}^{*}$ as before. Figure 11 shows a comparison of the frequency of occurrence of low- $P$ * air at two levels during January and July computed from both the NCEP-NCAR reanalysis and the NARR reanalysis datasets for the years 1979-2004. While the higherresolution dataset gives more spatially detailed information, the results are generally similar. However, the 
(a) January $350 \mathrm{hPa}$

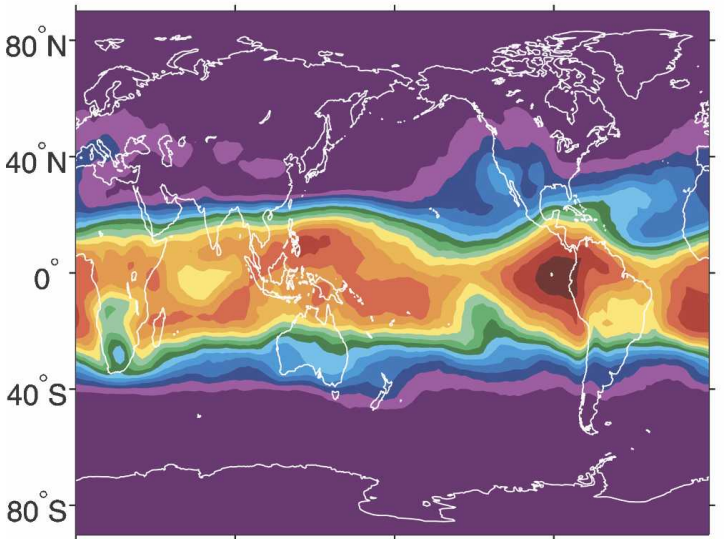

(c) January $550 \mathrm{hPa}$

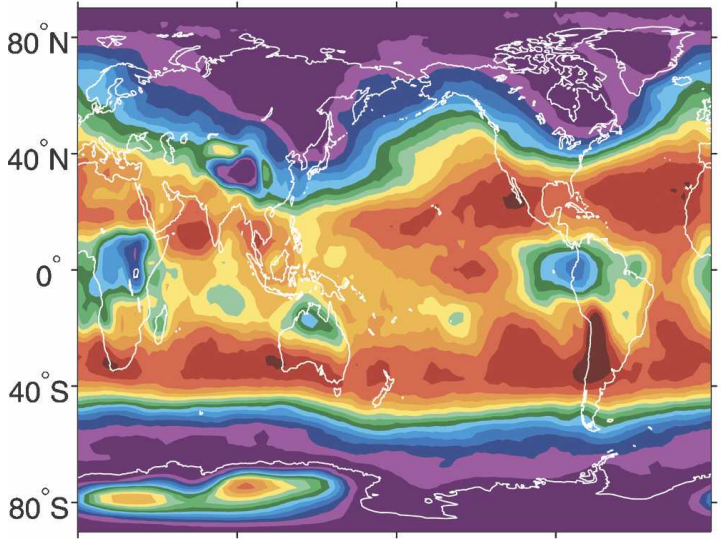

(e) January $775 \mathrm{hPa}$

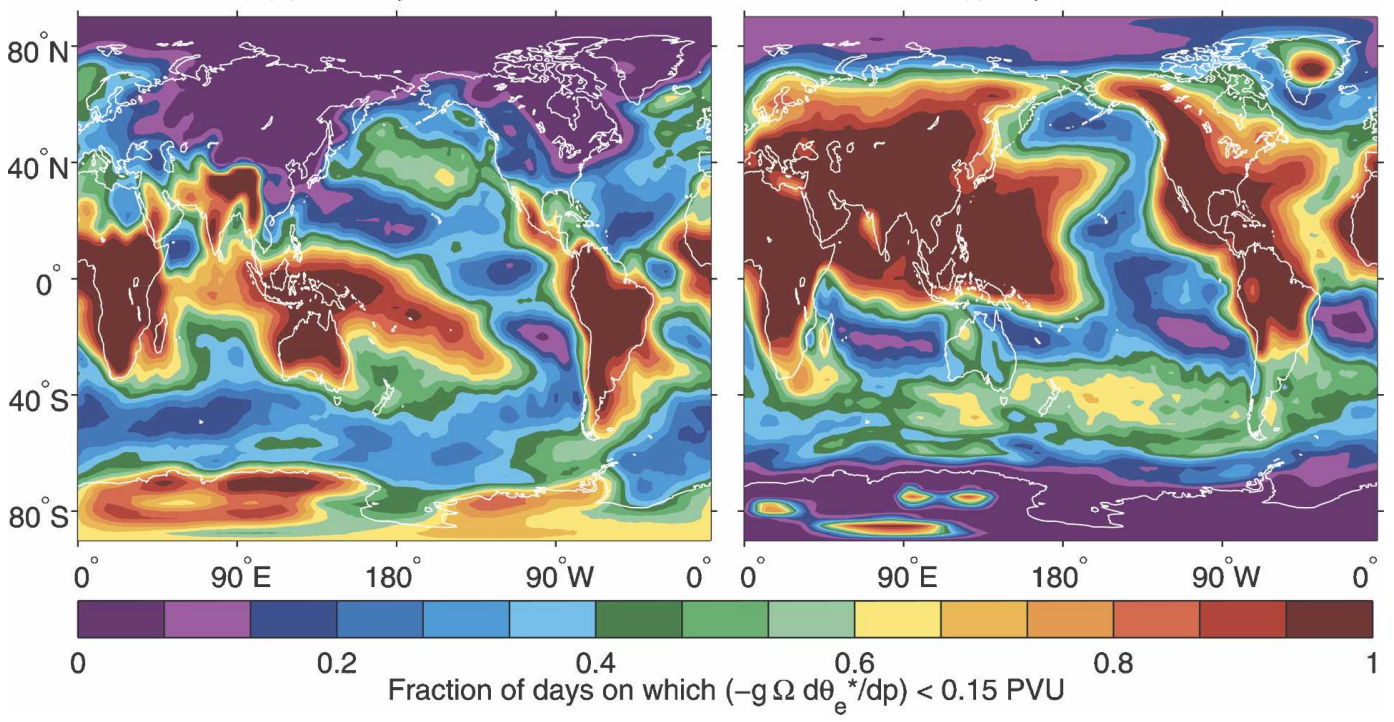

FIG. 10. Same as Fig. 9, but for $-g \Omega \partial_{p} \theta_{e}^{*}<0.15$ PVU. (b) July $350 \mathrm{hPa}$

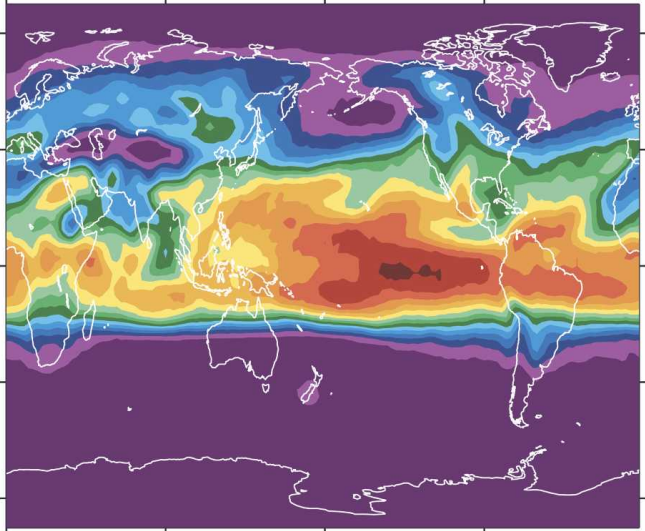

(d) July $550 \mathrm{hPa}$

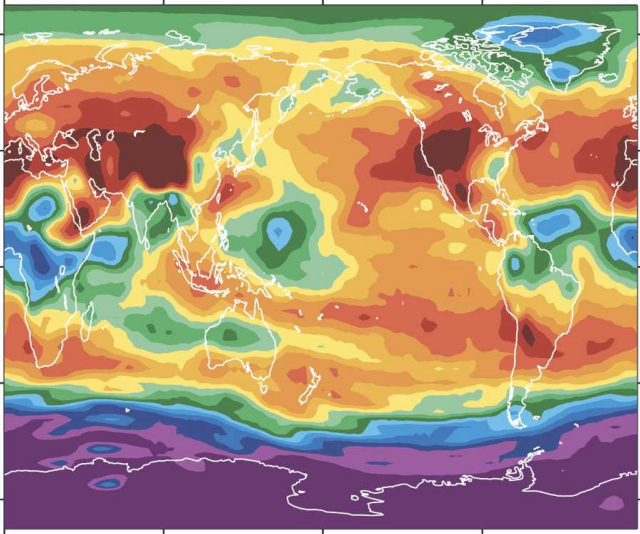

(f) July $775 \mathrm{hPa}$ results from the coarse-resolution dataset appear to overestimate the frequency of occurrence of convection over the subtropical oceans.

While we have not examined any trends in this analy- sis, we can speculate about how the results might change with climate. Frierson (2006) analyzed general circulation model simulations of global warming and found that the dry bulk stability increases with increas- 
(a) January $550 \mathrm{hPa}$ (NCEP/NCAR)

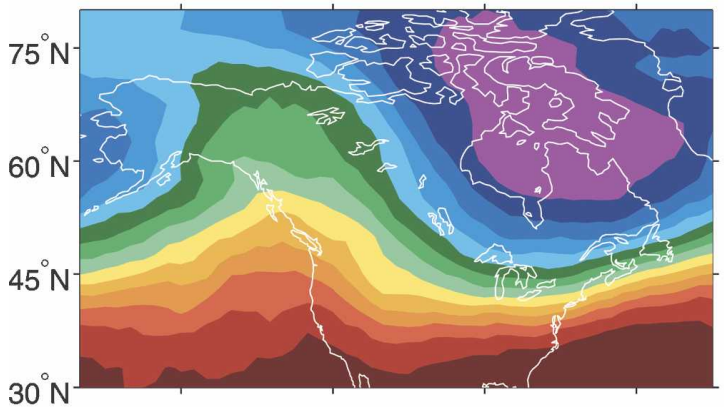

(c) January $775 \mathrm{hPa}(\mathrm{NCEP} / \mathrm{NCAR})$

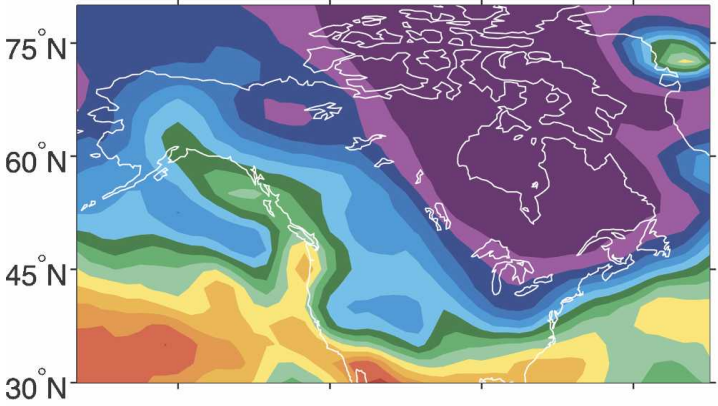

(e) July $550 \mathrm{hPa}$ (NCEP/NCAR)

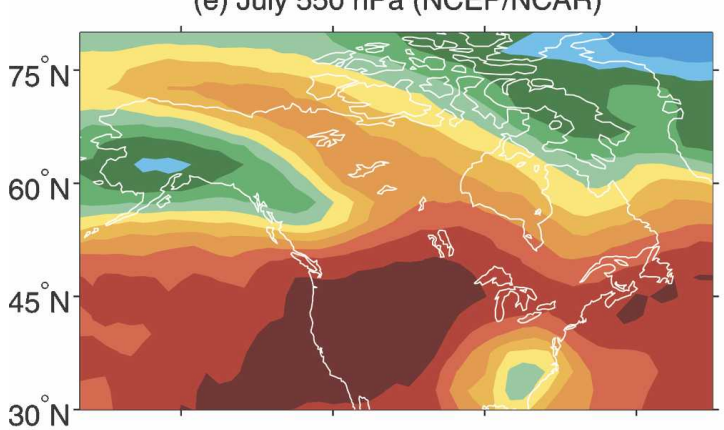

(g) July 775 hPa (NCEP/NCAR)

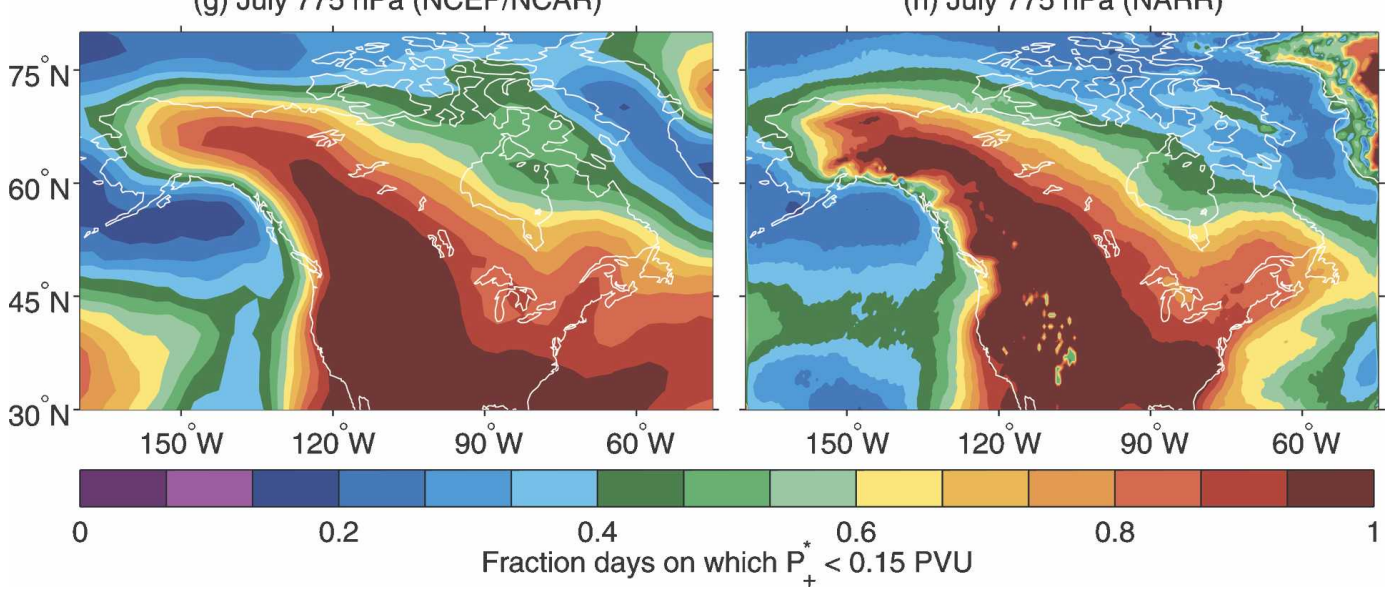

FIG. 11. Fraction of the days (1979-2004) on which $P_{+}^{*}<0.15 \mathrm{PVU}$ (a) in January at $550 \mathrm{hPa}$ from NCEP-
NCAR; (b) same as in (a), but from NARR; (c) in January at $775 \mathrm{hPa}$ from NCEP-NCAR; (d) same as in (c), but

FIG. 11. Fraction of the days (1979-2004) on which $P_{+}^{*}<0.15 \mathrm{PVU}$ (a) in January at $550 \mathrm{hPa}$ from NCEP-
NCAR; (b) same as in (a), but from NARR; (c) in January at $775 \mathrm{hPa}$ from NCEP-NCAR; (d) same as in (c), but from NARR; (e) in July at $550 \mathrm{hPa}$ from NCEP-NCAR; (f) same as in (e), but from NARR; (g) in July at $775 \mathrm{hPa}$ from NCEP-NCAR; and $(\mathrm{h})$ same as in $(\mathrm{g})$, but from NARR.

(b) January $550 \mathrm{hPa}$ (NARR)

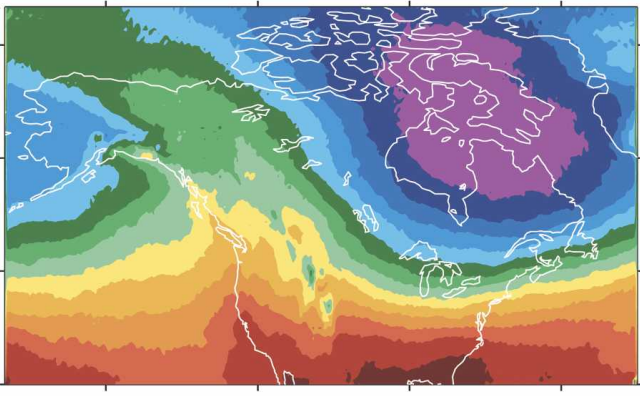

(d) January $775 \mathrm{hPa}$ (NARR)

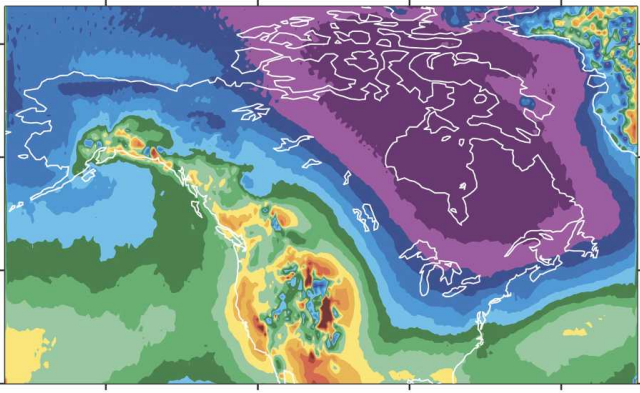

(f) July $550 \mathrm{hPa}$ (NARR)

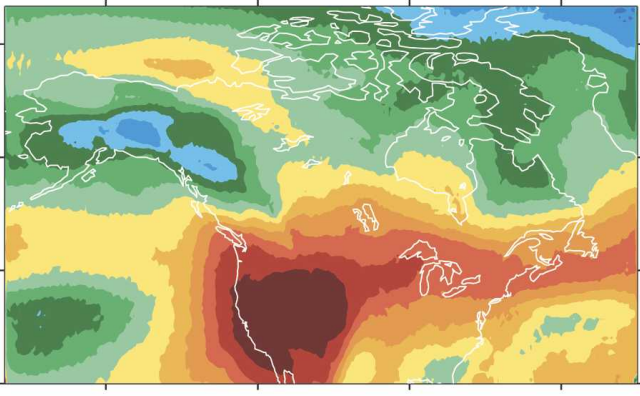

(h) July $775 \mathrm{hPa}$ (NARR) from NCP-NCAR; and (h) same as in (g), but from NARR. 
ing temperatures and increasing moisture content. He found that increases in midlatitude stability are accompanied by an increase in $\theta_{e}^{*}$ that is approximately constant with height. From the perspective of our analysis and consistent with Frierson's findings, we expect that in extratropical air masses that are frequently convectively neutral, the mean dry static stability would increase with increasing surface entropy.

Given that convectively neutral air masses can be found frequently in many parts of the extratropics, it is natural to ask what the relative importance of convection and eddies in maintaining the thermal stratification is. To answer this question, one needs to know the relative magnitude of convective and eddy entropy fluxes. Large-scale observations of the convective fluxes are lacking, but general circulation models may provide a means by which this question can be answered.

Acknowledgments. We thank Kerry Emanuel for sharing numerous insights and beneficial conversations about this topic with us. Anthony Del Genio and two anonymous reviewers provided helpful comments on an earlier draft of this manuscript. We are grateful for support from the Davidow Discovery Fund and the National Science Foundation (Grant ATM-0450059).

\section{REFERENCES}

Barry, L., G. C. Craig, and J. Thuburn, 2000: A GCM investigation into the nature of baroclinic adjustment. J. Atmos. Sci., 57, 1141-1155.

Bennetts, D. A., and B. J. Hoskins, 1979: Conditional symmetric instability-A possible explanation for frontal rainbands. Quart. J. Roy. Meteor. Soc., 105, 945-962.

Emanuel, K. A., 1983a: The Lagrangian parcel dynamics of moist symmetric instability. J. Atmos. Sci., 40, 2368-2376.

__ 1983b: On assessing local conditional symmetric instability from atmospheric soundings. Mon. Wea. Rev., 111, 20162033.

— 1988 : Observational evidence of slantwise convective adjustment. Mon. Wea. Rev., 116, 1805-1816.

—_ 1994: Atmospheric Convection. Oxford University Press, 580 pp.

— 2008: Back to Norway. Sanders Symposium Monograph, Meteor. Monogr., No. 55, Amer. Meteor. Soc., in press.

Ertel, H., 1942: Ein neuer hydrodynamischer Wirbelsatz. Meteor. Z., 59, 271-281.

Frierson, D. M. W., 2006: Robust increases in midlatitude static stability in simulations of global warming. Geophys. Res. Lett., 33, L24816, doi:10.1029/2006GL027504.

Frisius, T., 2005: An atmospheric balanced model of an axisymmetric vortex with zero potential vorticity. Tellus, 57A, 5564.

Gutowski, W. J., Jr., 1985: Baroclinic adjustment and midlatitude temperature profiles. J. Atmos. Sci., 42, 1733-1745.

_, L. Branscome, and D. Stewart, 1989: Mean flow adjustment during life cycles of baroclinic waves. J. Atmos. Sci., 46, 1724 1737.

Held, I. M., 1982: On the height of the tropopause and the static stability of the troposphere. J. Atmos. Sci., 39, 412-417.

Hoskins, B. J., M. E. McIntyre, and A. W. Robertson, 1985: On the use and significance of isentropic potential vorticity maps. Quart. J. Roy. Meteor. Soc., 111, 877-946.

Juckes, M. N., 2000: The static stability of the midlatitude troposphere: The relevance of moisture. J. Atmos. Sci., 57, 30503057.

Kalnay, E., and Coauthors, 1996: The NCEP/NCAR 40-Year Reanalysis Project. Bull. Amer. Meteor. Soc., 77, 437-471.

Lindzen, R. S., 1993: Baroclinic neutrality and the tropopause. $J$. Atmos. Sci., 50, 1148-1151.

_ B. Farrell, and K.-K. Tung, 1980: The concept of wave overreflection and its application to baroclinic instability. J. Atmos. Sci., 37, 44-63.

Manabe, S., and R. T. Wetherald, 1975: The effects of doubling the $\mathrm{CO}_{2}$ concentration on the climate of a general circulation model. J. Atmos. Sci., 32, 3-15.

Mesinger, F., and Coauthors, 2006: North American regional reanalysis. Bull. Amer. Meteor. Soc., 87, 343-360.

Sarachik, E. S., 1985: A simple theory for the vertical structure of the tropical atmosphere. Pure Appl. Geophys., 123, 261-271.

Schneider, T., 2004: The tropopause and the thermal stratification in the extratropics of a dry atmosphere. J. Atmos. Sci., 61, 1317-1340.

— , 2007: The thermal stratification of the extratropical troposphere. The Global Circulation of the Atmosphere, T. Schneider and A. H. Sobel, Eds., Princeton University Press, 47-77.

_ , and C. C. Walker, 2006: Self-organization of atmospheric macroturbulence into critical states of weak nonlinear eddyeddy interactions. J. Atmos. Sci., 63, 1569-1586.

Schubert, W. H., S. A. Hausman, M. Garcia, K. V. Ooyama, and H.-C. Kuo, 2001: Potential vorticity in a moist atmosphere. $J$. Atmos. Sci., 58, 3148-3157.

Sherwood, S. C., J. R. Lanzante, and C. L. Meyer, 2005: Radiosonde daytime biases and late-20th century warming. Science, 309, 1556-1559.

Simmons, A. J., A. Untch, C. Jakob, P. Kållberg, and P. Undén, 1999: Stratospheric water vapour and tropical tropopause temperatures in ECMWF analyses and multi-year simulations. Quart. J. Roy. Meteor. Soc., 125, 353-386.

Stone, P. H., 1978: Baroclinic adjustment. J. Atmos. Sci., 35, 561571.

- and J. H. Carlson, 1979: Atmospheric lapse rate regimes and their parameterization. J. Atmos. Sci., 36, 415-423.

_ , and B. Nemet, 1996: Baroclinic adjustment: A comparison between theory, observations, and models. J. Atmos. Sci., 53, 1663-1674.

Thorpe, A. J., and R. Rotunno, 1989: Nonlinear aspects of symmetric instability. J. Atmos. Sci., 46, 1285-1299.

Valdes, P. J., and B. J. Hoskins, 1989: Linear stationary wave simulations of the time-mean climatological flow. J. Atmos. Sci., 46, 2509-2527.

Vallis, G. K., 1988: Numerical studies of eddy transport properties in eddy-resolving and parametrized models. Quart. J. Roy. Meteor. Soc., 114, 183-204.

Xu, K.-M., and K. A. Emanuel, 1989: Is the tropical atmosphere conditionally unstable? Mon. Wea. Rev., 117, 1471-1479. 